\title{
Impact of EU Gender Equality Policy on Albanian Economic Development
}

\author{
PhD. Cand. Reina Zenelaj Shehi
}

\author{
Lecturer, Department of Political Science and International Relations, Epoka University, Tirana, Albania \\ rzenelaj@epoka.edu.al
}

PhD. Cand. Erinda Imeraj

Research Assistant, Department of Banking and Finance, Epoka University, Tirana, Albania

eimeraj@epoka.edu.al

\section{Doi:10.5901/ajis.2014.v3n3p146}

\begin{abstract}
Lack of economic development, unemployment and lack of work-life balance between woman and men has been one of the main challenges of Western Balkan countries. Their fragile internal political and economic structure has made external actors be very powerful in shaping national policies. In the last fifteen years, European Union has been the main promoter of reforms that can bring the countries of the region closer in line with the EU. The main goal of this paper was to firstly look at the EU gender equality policy in the Western Balkans that applies to Albania as well, and assess its compatibility with the real concerns of Albanian woman. Secondly, the study measured the impact of the first policy, i.e. women inclusion in the labor market, on the economic growth of Albania. This research employed a quantitative methodology based on surveys and a regression analysis. Surveys were conducted with 537 female in Albania clustered mainly according to age and geographical location. Regression analysis was based on official statistical data of the women employment and annual real growth of GDP of Albania in a range of ten years. The results showed that Albanian women are mostly concerned with the lack of economic development and their expectation is that the EU accession policies should primarily address that. In addition to that, the study found out that there exist a direct and positive relationship between women inclusion in the labor market and economic growth. Therefore, EU gender equality agenda covers the main needs of Albanian women as women employment means higher economic growth and less inequality that are factors of economic development.
\end{abstract}

Keywords: Gender Equality, EU Policy, Women Employment, GDP Growth, Albania.

\section{Introduction}

Albania is a small country with a young open economy. Since 1992, Albania operates as a democratic country with an open trade. For years, the main political and economic goal of the Albanian state has been the EU Accession. As such, the Albanian political framework has developed toward incorporating any necessary law or regulation as part of EU integration process. One of the most essential requirements for the Albanian democracy and its road toward EU has been the adoption and implementation of EU gender equality framework.

Gender equality is not a concept that works only as a fundamental human right but it also acts as an essential tool for the alleviation of poverty in a country and obviously for its economic growth. The contrary has been an evidence for many studies. Countries that have improved the role and the status of the women were a step ahead to stronger economic growth. Governments should tend to implement more policies toward the gender equality, as it needs to be valued for the determinant effect on the poverty or the economic growth of a country.

People of the same economy must have same opportunities to contribute equally to the improvement of an economy. In many countries the economic development and gender equality have been improved in parallel motion. According to many countries or societies, the women's access to different sectors as health care, employment, education etc, have limit the space between the women and men in the economic opportunities and this obviously have increase the impact in the economic development and growth. (Cathan House; Vivid Economics, 2010)

The EU Gender Equality policy has evolved from a focus on women's issues to gender relations and the need to transform the traditional gender perception. (S, 2009)The first interconnectedness of gender equality policy with economic development has been incorporated in the Treaty of Amsterdam (1997) and that expects to lead to policies that affect employment as well as other gender related fields.

The main goal of this paper is to firstly look at the EU gender equality policy in the Western Balkans with a special focus on Albania, and assess its compatibility with the real concerns of Albanian woman. Secondly, the study measures 
the impact of the first policy, i.e. women inclusion in the labor market, on the economic growth of Albania. It starts with an overall evaluation on the current Albanian legislation in respect to gender equality and then it searches the changes in male and female employment in Albia over years. Then the impact of the Gender Equality on the economic growth of the Albanian is statistically observed over the regression analysis that will be focused on the data of the labor market and the economic growth of Albania in a rage of 10 years. Concluding with the real impact on percentage unit of the gender equality in the economic growth of Albania, the research will present some policy recommendations in order to reach the narrowest difference on gender and a stronger development.

\section{Literature Review}

EU Gender Equality Policy on the Western Balkans is built on three pillars;(1) Employment, that is about closing the gender gaps in employment and social protection including the gender pay gap. This pillar aims to meet the objectives of Europe 2020 Strategy especially in the areas of employment, education and promoting social inclusion through reduction of poverty and thus, contribution to labor force. (2) Work-Life Balance between Woman and man in order to promote gender equality and contribute to demographic challenges. (3) Violence against women that aims to combat all forms of violence against women in order to ensure full enjoyment by women of their human rights. (Strategy for equality between women and men , 2014)

The strong impact of gender equality policy on the economic growth is briefly affirmed from many studies and real statistical data. According to Series of the Women's Economic Empowerment study on the gender equality and the propoor link, there are some evidences that support the connection of the gender equality and growth. Firstly, the gender equality in education would increase the human capital in the society and the possibilities to allocate the resources would be better off. The study explains that the gender equality increases the economic growth indirectly through the improving of the health and education of the next generation. Supportive evidence deals with the fact that the smaller the gender gaps leads to more effective strategy to boost growth. Accordingly: "Growth as a result of higher gender equality in the labor market 'increases the size of the pie'", picked from the study explains the fact that some considerable losses might be leaded from the gender discrimination, so the economy would get through a loss that has came up from the women. Research suggests that if the women wages would be increased, by narrowing the barrier between the women and men, there would be a slice loss in the men wage but if the overall economy would be studied; there would be an "increase of the size of the pie". (SIDA, 2010)

The study of Agenon and Canuto covers the long-run impact of policies aiming the encouraging of the gender equality on the economic growth in Brasil. This research concluded that fostering gender equality, which may partly depend on the sides that groundwork creates in terms of the allocation of the women time and exchange power, may have an impact on the growth, as well as the health and education outcomes, in Brazil. (Ageon \& Otaviano, 2013)

Inspired by many studies, collaboration between Chathan House and Vivid Economics, have concluded on a brief study of the situation and brought some evidences for action. Gender equality is a critical fundamental of the social progress. There are some global development objectives dealing with gender equality, as it has been considered as a positive indication of economic and social development. Maternal mortality is a significant issue that should be reduced, as an aim to promote gender equality and empower women; that might not be reached at the current progress situation. The research brings out some indications on how the gender equality could impact the world economic growth by setting eight key factors. The factors as human and physical capital, competitive market, stability, infrastructure, the rule of law, availability to trade and investments and higher agricultural productivity, can be considered as the important conditions which would ensure strong economic performance. (Cathan House; Vivid Economics, 2010)

The correlation and the impact of the gender equality to the economic growth is a broad subject studied in many aspects and analyzed in many methodologies. The research of Raju, Morrison and Sinha covers the gender equality, poverty and economic growth. In conclusion to this relation the research shows that the gender equality effect on the economic growth in different forms and through various channels. Firstly, there is an increase in the quality of the human capital which would impact directly on the productivity of the labor force and other equivalent factors of production. Some studies cited in the research have concluded that in different societies the impact of schooling in women bring more effort in growth comparing to the men schooling. Another link of gender equality and the economic growth deals with the proper allocation of the economic inputs. The women discrimination brings big gaps in the right share and the reach of the needed growth. The correlation of economic growth and gender equality appears to be positive. The figure 1 below shows better the correlation and position of the capita GDP growth rates and gender equality by the female to male ration in HDIs. (Morrison, Raju, \& Sinha, 2007) 
Figure 1: Per capita GDP growth rates and gender equality

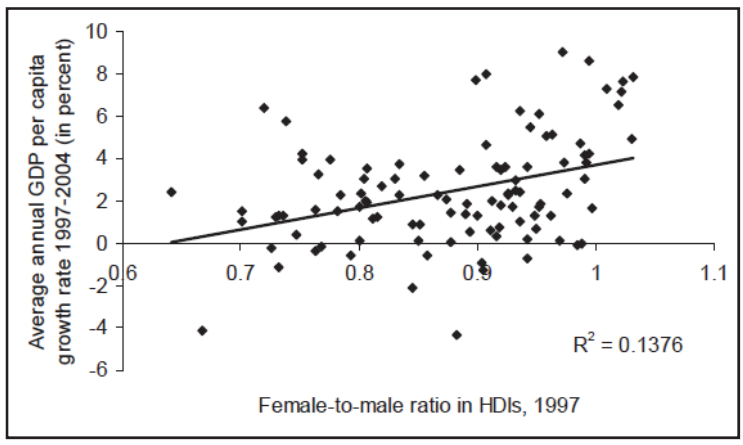

Source: (Morrison, Raju, \& Sinha, 2007)

In addition to the review of studies above, another study of (Goldman Sachs Institutional Portal, 2007)gives some specific statistical based data for the situation of this linkage of gender equality or inequality and the economic growth all over the world. According to the study the narrowing of the female and male employment would have a great effect for the global economy, as the increase of US GDP by approximately $9 \%$, Eurozone GDP by $13 \%$ and Japanese GDP by $16 \%$. In the past 10 years in European countries the increase of the female employment has been a key driver of the economic growth. The right policies of that increase had given a positive effect by increasing the total employment rate. Encouraging more female in the labor market has been very successful for most of the countries growth. The Eurozone is projected to keep rising the female employment and it would increase the economic growth by 0.25 percentage point. In Japanese it is projected to have $0.1 \mathrm{pp}$, showing slow progress in the female employment rate, while in US, where the young female employment has been fallen from the stats of the past 10 years is projected to have a boost to growth of 0 . Gender equality, mainly observed in the equal employment opportunities, so the rise of the female employment will continue to have important significance for equity market sector performance. Quoting: "Higher disposable income growth among women boosts, for instance, the consumption of luxury clothing and accessories." (Goldman Sachs Institutional Portal, 2007)

\section{Gender Equality Frameworks in Albania}

\subsection{The Legal Framework for Gender Equality in Albania}

Gender Equality is part of the highest legal act of Albania, the Constitution, from 1998; Article 18, which guarantees equality between the men and women before the law. The country endorsed the Convention on the Elimination of All Forms of Discrimination against Women (CEDAW) in 1993. Albania regularly reports to the CEDAW Committee on its progress in fulfilling with and implementing CEDAW provisions. As previously mentioned the European Union accession is an important goal for Albania and its legislation and policies of the gender equality are very essential for the process. Firstly, the basic step ahead initiated by the signing of the Stabilization and Association Agreement in 2006. As equality is one of the instructing principles of the EU, Albania's gender mainstreaming obligations are contained in the five policy areas spelled out in the EU Strategy for equality between women and men 2010-2015. (Van der Leest, Xhelo, \& Wittberger, 2012)

Legislation claims the equality between women and men also by the Law No. 9970 "On Gender Equality in Society", which entered into force in 2008. This law would adjust important issues of the equality between men and women in different aspects, starting from the public life, the equal treatment and equal opportunities and chances for their engagement and contribution in the improvement of all social circles. The aim of this law is to a) assure right protection against gender discrimination; b) define measures to guarantee equal opportunities for men and women in order to eliminate gender-related discrimination; and c) specify the responsibilities of state authorities at all levels for drafting and implementing normative acts and policies that support gender equality. This law introduces specific precautions in political and public decision making areas, as well as in other areas as employment and education. (The Assembly of the Republic of Albania, 2008) 
Gender equality is adjusted by two other laws in Albania as, Law No. 10221, "On Protection against Discrimination", adopted in 2010, and Law No. 9669 "On Measures against Violence in Family Relations", adopted in 2007. The first law prohibits discrimination in political, economic and social spheres not only on the grounds of race, ethnicity, disability or religion, but also on the grounds of sex, gender, gender identity and sexual orientation. The second law is designed to prevent and reduce domestic violence, and prescribes the adequate response to as well as services for victims. (Van der Leest, Xhelo, \& Wittberger, 2012)

\section{Research Methodology}

This study has two main assumptions.

(1) Gender Equality Policy can be successfully implemented if it meets the real needs of Albanian women and men. In order to identify Albanian women and men needs and interests, the study asks 537 females and 547 man from 8 different regions of Albania about the socio-political situation in Albania and their expectations on Albania -EU relationship.

(2) There is a positive correlation between gender equality and economic growth and development in all countries. There is a slight percentage point of growth that is caused from the gender equality. As previously mentioned from the data proceeded from the official site of statistics in Albania, research will consider a regression analysis between the GDP growth rate of Albania from 2000 to 2011 and the data of the labor market mainly the Female and Male percentage employment, basically focused on the female employment rate from year 2000 to 2011. (INSTAT, 2013)

\section{Analysis and Discussion}

\subsection{Albanian Gender Perceptions and Expectations on EU}

When asked about the main problem of Albania $53.7 \%$ of female and $46.3 \%$ of male consider the lack of economic development to be the main problem of Albania. (Yenigun, Baltaci, \& Ozcan, 2011)For both the majority of Albanian women and men, economic development is the most important issue and as such their first need. Additionally, $89.4 \%$ of female and $94.4 \%$ of Albanian men want Albania to become a member of European Union. The finding shows that a very high percentage of both men and female wants Albania to be a member of EU ; thus EU is a very legitimate external actor in the eyes of Albanian men and women. Legitimacy helps in promoting the messages better and quicker. $47 \%$ of female and $50.3 \%$ of male believe that EU membership would improve Albanian economy showing that for the first main expectations of Albanian women and men is economic development. When it comes to security expectations, only a few see it as a priority in terms of EU-Albanian relations. Only $6 \%$ of female and $3.9 \%$ of male don't want Albania to be a member of European Union. Among that Females mostly disagree because they think that Albania will lose the cultural values whereas male mostly believe that nothing will change. Nevertheless the numbers are too low and they don't risk EU's legitimacy as a strong promoter.

To conclude, the main findings cite that according to Albanian women, lack of economic development is one of the crucial concerns in their country and EU accession process should primarily address that. While, a lot of them evaluate internal politics as problematic as well, as a matter of fact very few consider their security in threat. When asked about EU membership, the majority of women and men claimed that EU membership should improve their economy. While only $15.4 \%$ of female asserted that it should increase safety. EU gender equality program designed for the Western Balkans is assessed to have addressed Albanian women perception as two out of three main reform headings focus on employment and work- life balance between woman and men but violence against woman, which is the third main reform heading, is far from being their real concern

\section{Gender Equality Policy and Its Interconnectedness to Labor Market and Economic Growth in Albania}

According to the main official data regarding the Labor market in Albania, INSTAT, labor market and the employment and unemployment rates reflect gender relations among the coverage of special roles and percentages of women and men. This does divide and shows up the concentration of differences between men and women in different sectors of labor market. Women are part of the basic part of textile sector workers and a high number of the service sector workers. When there is a study of the distribution of the men and women workers across main sectors (agriculture, construction, services etc), there should be a search also on the distribution of men and women through different positions in job hierarchies. 
Therefore it is important to study the labor market not only in the plain structure but also in the "logic" it has been structured. (Sejdini, 2012)

Human Development Index (HDI) is a summary of measures in the long term progress in three basic dimensions of human development as the long and healthy life, the access to knowledge and decent standard living. This index would mainly explain also the equality that exist between men and women and is taken in consideration as a right observatory. The HDI in Albania from 1980 to 2011 is positively increased from 0.6 to 0.748 . (UNDP, 2013)

Economic growth has been in an increasing motion in each year too. The data taken from the official site of statistics of Albania shows it. According to the data GDP annual growth rate for the 1980 year has been 2.684 and in the 2011 have been 3. (INSTAT, 2013)

According to the data above, the chart below will show the positive correlation that exists between the gender equality (HDI) and the GDP growth rate in Albania from 1980 to 2011 in a five year periodical collection.

Figure2. HDI and GDP growth rate in Albania.

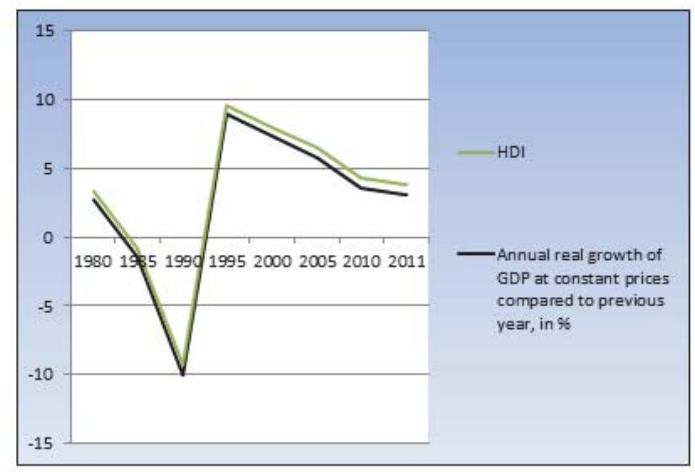

Source: (INSTAT, 2013)

According to the data above the regression analyses was applied and the below results are concluded:

\begin{tabular}{|c|c|c|c|c|c|c|}
\hline \multicolumn{2}{|l|}{ Summary Output } & & & & & \\
\hline \multicolumn{2}{|c|}{ Regression Statistics } & & & & & \\
\hline Multiple R & 0.954769597 & & & & & \\
\hline R Square & 0.911584984 & & & & & \\
\hline Adjusted R Square & 0.893901981 & & & & & \\
\hline Standard Error & 0.881247289 & & & & & \\
\hline Observations & 7 & & & & & \\
\hline \multicolumn{7}{|l|}{ ANOVA } \\
\hline & $d f$ & SS & $M S$ & $F$ & Significance $F$ & \\
\hline Regression & 1 & 40.03471 & 40.03471 & 51.55148 & 0.000816 & \\
\hline Residual & 5 & 3.882984 & 0.776597 & & & \\
\hline \multirow[t]{2}{*}{ Total } & 6 & 43.9177 & & & & \\
\hline & Coefficients & Standard Error & $t$ Stat & $P$-value & Lower 95\% & Upper 95\% Lower 95.0\% Up \\
\hline Intercept & -5.820385436 & 7.674147 & -0.75844 & 0.482386 & -25.5474 & $\begin{array}{lll}13.90664 & -25.5474 & 1\end{array}$ \\
\hline 66 & 0.910446639 & 0.126804 & 7.179936 & 0.000816 & 0.584486 & $0.584486 \quad 1.236407$ \\
\hline
\end{tabular}

The linear regression equation is as follows:

\section{$Y=\alpha+\beta^{*} X+\varepsilon$}

Where:

(Y) The dependent variable $=$ GDP growth rate

$(X)$ The independent variable = Female employment

( $\beta$ ) The coefficient of the independent variable

(a) Intercept parameter

$(\varepsilon)$ The standard error 
The summary output of the regression is in the Annex according to the result the graph below shows the negative relation of the two variables.

$X$ Variable coefficient $=0.910446639$

Intercept coefficient $=-5.820385436$

R Square $=0.911584984$

Standard Error $=0.881247289$

t Statistics $=-0.75844$

So, estimated regression equation is as follows:

$\mathrm{Y}_{\mathrm{t}}=-5.820385436+0.910446639^{*} \mathrm{X}_{\mathrm{t}}$

Due to results of the analyses there is the expected observation of a slight impact of the gender equality to the economic growth. So the change, as we expected the female employment, has a slight impact on the economic growth even though in small percentage point. The graph below would consider showing also the Residual graph, presenting how much deviates the observation through the expected values.

Figure3. Line Fit Plot.

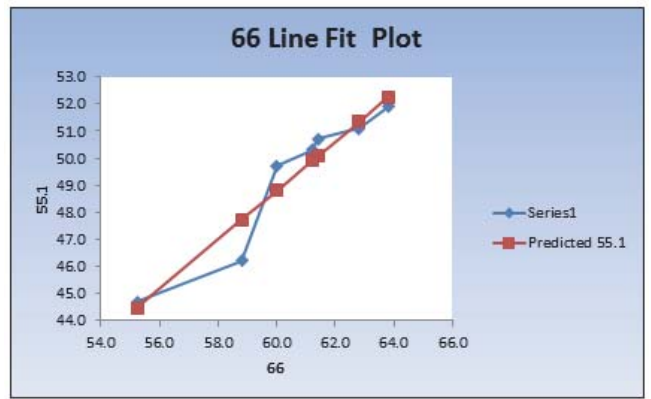

\section{Conclusion}

Aim of the research was to study the impact or the effect of the gender equality to the economic growth. Considering all the overview and the real statistical data observation, it can be concluded that there exists an impact of the gender equality to the economic growth of Albania. Albanian economic is small and there exists many factors affecting its economic growth and development but with the improvement of the gender equality policies it is expected to have higher economic growth and as well as an improvement of the social development. The impact in the last 10 years is considered to be slight but the positive correlation gives high potential to accept the impact of the equality between men and women in the economic growth and development in Albania.

\section{References}

a. (a). a. a: a.

Ageon, P. R., \& Otaviano, C. (2013). Gender Equality and Economic Growth in Brasil. The World Bank Poverty Reduction and Economic Management Network, wps 6348.

Cathan House; Vivid Economics. (2010). Gender Equality and Economic Growth: Evidence for Action . United Kingdom Department for International Development .

Goldman Sachs Institutional Portal. (2007). Gender Inequality,Growth and Global Ageing. Global Economics Paper , No: 154.

INSTAT. (2013). NAtional Account Data. Albanina Statistical Institute.

Morrison, A., Raju, D., \& Sinha, N. (2007). Gender Equality, Poverty and Economic Growth. The World Bank, Gender and Development Group, Poverty Reduction and Economic Management Network, 31-37.

Office of the Equal Opportunities Ombudsman. (2006). GENDER EQUALITY IN EUROPEAN UNION. European Union .

S, S. (2009). European Gender Regimes and Policies: Comparative Perspectives. Farnham: Ashgate.

Sejdini, I. (2012). THE LABOUR MARKET TRENDS IN ALBANIA: THE WAYS TO INTEGRATE A GENDER PERSPECTIVE INTO WORKPLACES AND LABOUR POLICIES. INTERNATIONAL JOURNAL OF SOCIAL SCIENCES AND HUMANITY STUDIES Vol 4, No $2,265-274$.

SIDA. (2010). Gender Equality and Pro-Poor Growth. Women's Economic Empowerment Series , 1-4.

Strategy for equality between women and men . (2014, June 5). Retrieved from European Commission: http://ec.europa.eu/justice 
Igender-equality/document/index_en.htm

The Assembly of the Republic of Albania. (2008). Law No. 9970 "Gender Equality In Society" . Albanian Constitution .

UNDP. (2013). Albania, HDI values and rank changes in the 2013. Human Development Report.

Van der Leest, K. J., Xhelo, R., \& Wittberger, D. (2012). Gender Equality and Local Governance. Ministry of Labour, Social Affairs and Equal Opportunities.

Yenigun, C., Baltaci, C., \& Ozcan, S. (2011). Albanian Public Perceptions of Socio- Cultural and Foreign Policy Issues . Center for European Studies, Political Science and Internatioal Relations. Tirane: Epoka University. 